\title{
EXPERIMENTAL TESTING OF REINFORCED CONCRETE SLABS RETROFITTED WITH CFRP AND MECHANICAL ANCHORS
}

\author{
GENEVIEVE PEZZOLA \& LAUREN STEWART \\ School of Civil and Environmental Engineering, Georgia Institute of Technology, USA
}

\begin{abstract}
The ongoing presence and persistence of terrorist groups is a perpetual threat that emphasizes the urgency to strengthen and retrofit any structural vulnerabilities, especially vulnerabilities that when exploited could lead to catastrophic damage of expensive infrastructure or loss of life. To avoid these losses, the application of fiber-reinforced polymer (FRP) laminates as a retrofit on reinforced concrete (RC) structural elements has been proven to increase the blast resistance. There have been few studies, however, on the anchorage behavior in large-scale RC systems retrofitted with FRP subjected to blast. To bridge this gap, two different mechanical anchorage techniques for concrete structures using carbon fiber-reinforced polymer (CFRP) layers were subjected to explosive loading to investigate system behavior with the different mechanical anchorage retrofits: a steel strap retrofit system and smaller steel plate retrofit system. The experimental program utilized a hemisphere $\mathrm{C} 4$ charge and tested the retrofit with scaled distances of $1.42 \mathrm{~m} / \mathrm{kg}^{1 / 3}$ and $1.09 \mathrm{~m} / \mathrm{kg}^{1 / 3}$. The performance of the two blast retrofits were evaluated and compared in terms of the displacements of the slab systems and associated failure modes.

Keywords: blast, CFRP, reinforced concrete, debonding.
\end{abstract}

\section{INTRODUCTION}

The application of fiber-reinforced polymer (FRP) laminates have been shown to increase the flexural strength of beams, columns, and slabs, as well as the blast resistance [1]-[4]. FRP has many properties that make it advantageous for use for blast retrofits. It can be installed post-construction, it can be installed quickly, it has high stiffness and high tensile strength [5], [6]. For large structures, anchors must be installed not just at the supports but throughout the component. Anchoring prevents or delays delamination or debonding failures of the FRP and helps the FRP achieve its full tensile capacity. There have only been few studies that investigate the behavior of systems with anchors installed not just near the boundary conditions, and none of these studies have subjected these types of systems to actual blast loads [7].

As FRP tensile failures are rarely observed [8], parameters that affect the properties of debonding and delamination (i.e., the performance of anchors), are extremely important to understand as they can influence the failure modes of the system. Anchors can induce stress localizations that can cause tearing of the FRP, and can also initiate the delamination of the FRP [1]- [10]. When the FRP debonds from the concrete substrate, the effective increase in blast resistance is lowered, and therefore the system is not as efficient as it otherwise could be.

\section{EXPERIMENTAL PROGRAM}

Two slabs with two different mechanical anchorage systems were constructed and subjected to a C4 hemispherical surface burst. Each slab had four layers of CFRP applied to the nonblast side and a different mechanical anchorage system applied to prevent or delay debonding of the CFRP. One mechanical anchorage system had three steel straps that spanned the width of the specimen and were placed at the quarter points of the slab and the mid-height of 
the slab. This steel strap mechanical anchorage system was chosen as it was very similar to the in-field application of this retrofit that was of interest in this research. The straps were $10.16 \mathrm{~cm}(4 \mathrm{in})$ tall and $1.6 \mathrm{~cm}(5 / 8 \mathrm{in})$ thick. This mechanical anchorage system is herein referred to as the "strap anchorage system," and the test for this specimen is referred to as FT1. The other mechanical anchorage system had 17 steel plates that were placed at various heights and widths throughout the slab. This small steel plate mechanical anchorage system was chosen in order to investigate a different mechanical anchorage system that would have a less cumbersome installation process, utilize less steel, and potentially distribute the stresses more evenly across the retrofit than the steel strap mechanical anchorage system. The location of these mechanical anchors were chosen to be evenly distributed across the specimen, and were placed at the mid-height, quarter points (similar to the location of the strap anchorage system), as well as at the eighth points. The number of anchors were chosen due to a preliminary finite element analysis that was conducted which estimated that placing additional mechanical anchors at the eighth points allowed for similar displacements to be obtained between the two different mechanical anchorage systems, given the same loading conditions.

The steel plates were $10.16 \mathrm{~cm}$ (4 in) wide, $10.16 \mathrm{~cm}$ (4 in) tall, and $1.6 \mathrm{~cm}(5 / 8$ in) thick. This mechanical anchorage system is herein referred to as the "plate anchorage system," and the test for this specimen is referred to as FT2. A scaled distance was selected such that the blast load would inhibit a flexural failure mode with tensile cracking in the concrete, to gather data to better understand the mechanics of CFRP retrofits, and observe the behavior of two different anchorage systems.

The US Army Engineer Research and Development Center (ERDC) designed and constructed a non-responsive reaction structure for a previous test series. This reaction structure was designed with a long and narrow opening (1.69 m (66.375 in) by $3.98 \mathrm{~m}$ $(156.5 \mathrm{in}))$ in the middle to place a specimen. This opening, as well as the impulse that this reaction structure was designed for, restricted the dimensions of the specimen for this test series.

\subsection{Test specimen}

Two identical reinforced concrete slabs were constructed $1.67 \mathrm{~m}$ (65.75 in) wide, 3.9 (153.75 in) tall, and $15.2 \mathrm{~cm}$ (6 in) thick. The two specimens were reinforced for flexure symmetrically with five \#5 rebar spaced at $36.8 \mathrm{~cm}$ (14.5 in) with $2.54 \mathrm{~cm}$ ( 1 in) clear cover. The specimens were heavily reinforced to prevent shear failure with 31 \#5 rebar spaced at $12.7 \mathrm{~cm}$ (5 in). The specimen were cast with SAC-5 concrete with a nominal compressive strength of $34.47 \mathrm{MPa}(5,000 \mathrm{psi})$ (the 28-day strength was $31.1 \mathrm{MPa}(4,510 \mathrm{psi})$ ).

\subsubsection{Retrofit installation}

Three weeks after the concrete was poured, epoxy anchors were installed in the two specimen. The epoxy, HIT-RE 500 Epoxy Adhesive, was injected to fill three-quarters of the $1.9 \mathrm{~cm}$ ( $3 / 4$ in) cored holes, and then a HAS-R 304 stainless steel $1.6 \mathrm{~cm}(5 / 8 \mathrm{in})$ anchor bolt was placed into each hole with epoxy and not touched again until after the initial curing time was reached.

A day after the epoxy anchors were installed, four layers of MasterBrace ${ }^{\circledR}$ FIB 600/50 CFS were applied to the back face of both specimen. The guidelines provided by the manufacturer were followed to best install the unidirectional CFRP. Previously measured and cut strips of CFRP were then applied onto the specimen using a roller to push the fabric into the saturant to fully saturate the fabric. After a layer of fabric was installed, another layer of saturant was applied. These two steps were repeated until four layers of fabric were installed 
(the first two layers had the fibers parallel to the height of the specimen and the second two layers had the fibers parallel to the width of the specimen, resulting in a $0^{\circ}-0^{\circ}-90^{\circ}-90^{\circ}$ layup of the CFRP).

The mechanical anchors were applied after the CFRP cured. For both anchorage systems, the edges of the steel were rounded with a grinder to prevent any sharp edges coming into contact with the CFRP. For the steel plate anchorage system, a thin piece of rubber $(0.32 \mathrm{~cm}$ (1/8 in) thick) was installed in between the CFRP and steel disc. The rubber was installed to allow a gentler transfer of forces between the CFRP and steel plate. Fig. 1 shows the finished retrofit for both specimen (the specimen with the strap anchorage system is shown on the left and the specimen with the plate anchorage system is shown on the right).

It should be noted that the installation of the steel strap anchorage system was not easy. It was anticipated that there would be some difficulty installing straps over post-construction installed epoxy anchors, so slots were designed into the steel straps to help the installation process. Even with slots for every hole, and very carefully measured and drilled holes for the epoxy anchors, the steel straps did not go on easily. A large mallet had to be used to get all three straps on the specimen.

\subsection{Instrumentation}

Two piezoelectric accelerometers were used for each test. The accelerometers were placed in a low-frequency foam insulator (LOFFI) mount which was then welded to the mechanical anchoring system of the specimen. LOFFI mounts are comprised of a series of rings of aluminum and elastomeric damping material so that the accelerometer data is not flooded with high-frequency data. The LOFFI mount was welded to the mechanical anchorage system. One $2,000 \mathrm{~g}$ accelerometer was placed near the mid-width of the specimen, $87.31 \mathrm{~cm}$ (34.375 in) from the bottom, and a $6,000 \mathrm{~g}$ accelerometer was placed near the mid-width of the specimen, $291.5 \mathrm{~cm}$ (114.75 in) from the bottom.

Ten precision strain gauges from Micro-Measurements were installed on each specimen. The strain gauges were general purpose linear pattern strain gauges with a gauge length of $5.1 \mathrm{~cm}(2 \mathrm{in}), 350 \pm .02 \%$ resistance $(\Omega)$, and constantan foil gauges with a thin, laminated, polyimide-film backing. The strain gauges had a strain limit of $+/-3 \%$ strain. Gaugekote \# 8
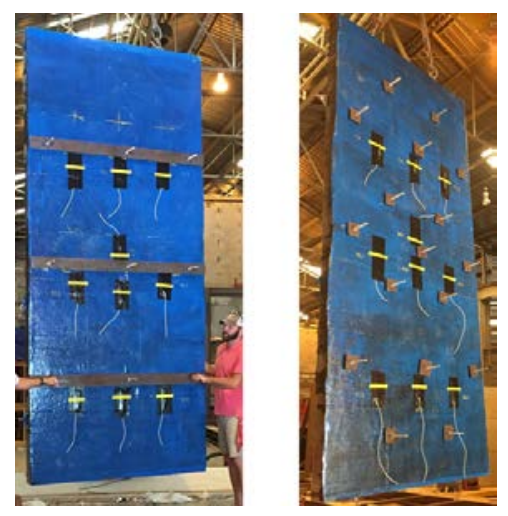

Figure 1: Finished strap anchorage retrofit (FT1 - left) and finished plate anchorage retrofit (FT2 - right). 
from Vishay Micro-Measurements was used as a weather protectant, using caution to leave the solder tabs exposed. The cable was soldered in place after the coating cured, and then an additional layer of coating was applied. Foam tape, aluminum tape, and Gorilla tape were installed on top of the strain gauge in that order as further weather protectant and mechanical protection. A strain relief was also installed to prevent the wires from breaking during the test. The bridge completion was then installed in the field.

Five rack and pinion displacement gauges were used to obtain displacement-time histories. Three rack and pinions were installed on one steel stand on the center line at the quarter points and two rack and pinions were installed on the other steel stand near the right edge, at the bottom quarter point and mid-height. Fig. 2 shows the placement of the accelerometers (outlined in circles), strain gauges (outlined in triangles), and rack and pinions (outlined in rectangles).

Six HKS pressure gauges were used to obtain free-field and reflected pressures. Two freefield gauges were installed in concrete cylinders topped with aluminum discs that were buried underground so that the gauge would be flush and level with the ground surface. One freefield gauge was placed one standoff away from the charge (rated for $1.72 \mathrm{MPa}(250 \mathrm{psi})$ ) and the other free-field gauge was placed two standoffs away from the charge (rated for $0.689 \mathrm{MPa}(100 \mathrm{psi})$ ). Four reflected pressure gauges (each rated for $13.79 \mathrm{MPa}(2,000 \mathrm{psi})$ ) were mounted into the front slab of the reaction structure surrounding the specimen. One pressure gauge was mounted below the specimen at the centerline, two pressure gauges were mounted at either side of the specimen at the mid-height, and the other pressure gauge was mounted above the specimen at the centerline. The layout of the free field pressure gauges and reflective pressure gauges is shown in Fig. 3.

Three high-speed Phantom cameras were used in each test. One high speed camera was set up for an overall view to observe the explosion and shock wave, with a 3,000 frames per second (fps) frame rate. The tripod legs for this camera were secured with sandbags. Two high speed cameras were setup to view inside the culvert of the reaction structure. One of these cameras $(4,200 \mathrm{fps})$ was setup in a previously built viewport with a protective glass casing to view the back side of the specimen. The other camera $(5,300 \mathrm{fps})$ was set up in a steel camera box and attached to the side of the culvert to obtain a side view of the specimen during the test.

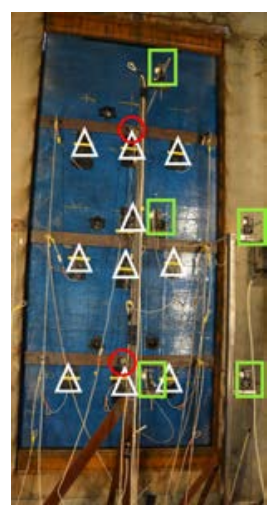

Figure 2: Instrumentation layout: Accelerometers outlined in circles, strain gauges outlined in triangles, and rack and pinions outlined in rectangles. 

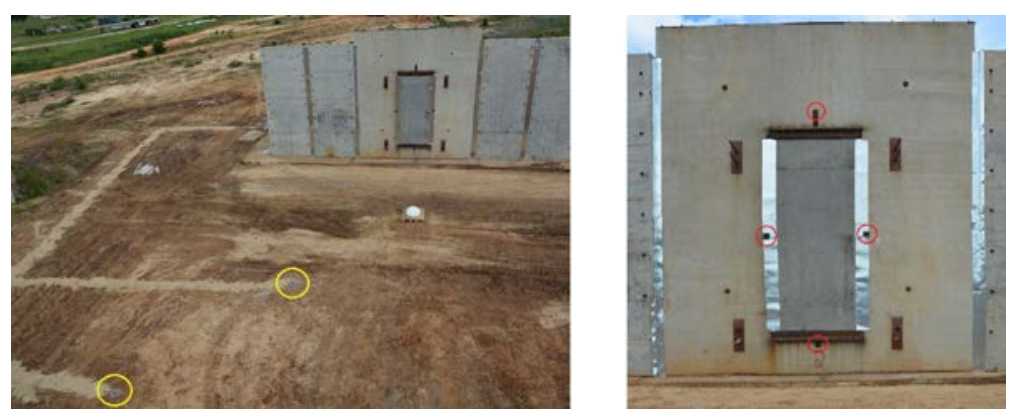

Figure 3: The two installed free field pressure gauges (left) and the layout of the four reflective pressure gauges (right).

\subsection{Test setup}

The reaction structure that was used in this test series is comprised of large reinforced concrete sections that are post-tensioned together. The front wall of the reaction structure

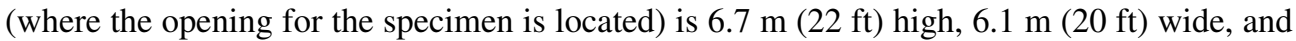
$0.3 \mathrm{~m}$ ( $1 \mathrm{ft})$ thick. The bottom of the opening is located $0.68 \mathrm{~m}$ (26.875 in) off of the ground. The opening was constructed such that a steel embed with anchor bolts embedded in the concrete outlines the opening, which allowed for structural steel to be welded to the steel embed. Boundary conditions were designed specifically for this test series to obtain one-way slab bending. No boundary conditions were constructed on the sides of the opening to allow the specimen to freely move along the whole length of the specimen. A one inch thick steel plate was welded to the bottom and top of the steel embed with a full length $1.9 \mathrm{~cm}(3 / 4 \mathrm{in})$ fillet weld. The steel plates had 11 holes drilled into the plates spaced six inches apart. The holes in the steel plate allowed for a L $6^{\prime \prime} \times 4^{\prime \prime} \times 3 / 4^{\prime \prime}$ steel angle with corresponding holes to be attached with bolts to restrain the front of the top and bottom of the specimen. On the back edge of the steel embed, a HSS $6^{\prime \prime} \times 4^{\prime \prime} \times 1 / 2^{\prime}$ section was welded to the bottom and top of the steel embed with two full length $1.9 \mathrm{~cm}$ (3/4 in) fillet welds. The HSS sections were put in place to restrain the back of the top and bottom of the specimen. Rubber was inserted in between the specimen and the steel plate, steel angle, and steel tubing.

Behind the front wall are three sections of culvert that are $1.22 \mathrm{~m} \mathrm{(4ft)}$ thick, totaling in $3.66 \mathrm{~m}(12 \mathrm{ft})$ of culvert. The culvert is $5.03 \mathrm{~m}(16.5 \mathrm{ft})$ tall. All sections of the culvert and the front slab are post-tensioned together with eight steel all-thread bars. Large clearing walls were also installed on both sides of the reaction structure to reduce any clearing effects.

It should be noted that this reaction wall has been used for a multitude of explosive tests, many above the impulsive loads it was designed for. Therefore, the reaction structure has visible cracks and is not perfectly straight or aligned with its adjacent reinforced concrete sections. It should also be noted that due to this damage, post-tensioning all eight bars did not entirely close up all of the gaps in the structure. As the reaction structure sections do not perfectly align, aluminum flashing was used to cover any gaps between the front slab of the reaction wall and the clearing walls to help prevent any clearing that might otherwise happen due to gaps.

A wooden block was constructed to make the $\mathrm{C} 4$ mold. Once the hemisphere was cut out of the block, glazing was applied to allow for a smooth finish on the charge. A layer of plastic wrap was placed inside the mold while the $\mathrm{C} 4$ was molded into the hemisphere 
using rubber mallets. The block was then placed on a table constructed from plywood that was $8.9 \mathrm{~cm}$ ( $3.5 \mathrm{in})$ tall. The whole setup was then laid down over the ground zero marker for each test, and all excess wood including the mold was removed so that only the hemispherical charge and small plywood table remained. Fig. 4 shows the finalized test setup before firing. The specimen with the strap anchorage retrofit (FT1) had a standoff of $6.4 \mathrm{~m}(21 \mathrm{ft})$ and the specimen with the plate anchorage retrofit (FT2) had a standoff of $5.03 \mathrm{~m}(16.5 \mathrm{ft})$. It was decided to change the standoff for FT2 after the completion of the FT1 test, in order to induce more damage and deformation in the FT2 slab to better understand how the plate mechanical anchorage system performed when the slab exhibited higher deformation.

\section{EXPERIMENTAL RESULTS}

Accelerometer, rack and pinion, strain gauge, pressure-time history, and qualitative data were recorded for the two tests. The peak unfiltered acceleration observed for FT1 was $561.1 \mathrm{~g}$ in the top accelerometer and 666.2 $g$ in the bottom accelerometer. The peak unfiltered acceleration observed for FT2 was $948.4 \mathrm{~g}$ in the top accelerometer and $1198.3 \mathrm{~g}$ in the bottom accelerometer. The peak strain obtained from the strain gauges in FT1 was $0.8 \%$, and the peak strain obtained from FT2 was $0.804 \%$. Some of the strain gauges broke after providing some reliable data in FT2, so it is likely that some higher strains were obtained than obtained from the gauges.

The maximum displacement of the midpoint for FT1 was approximately $11.4 \mathrm{~cm}$ (4.48 in), while the maximum displacement of the midpoint for FT2 was approximately $16.3 \mathrm{~cm}$ (6.4 in), measured using the rack and pinions. Fig. 5 shows the displacement-time histories for the midpoints of FT1 and FT2, where "DMR" and "DMM" refer to the rack and pinions placed on the right side of the slab and middle of the slab, respectively, for each test. The peak reflected pressures and impulses for both FT1 and FT2 are shown in Table 1, where the peak reflected pressures were obtained directly from the reflected pressure gauges and the peak reflected impulses were calculated by integrating the pressure-time histories from the reflected pressure gauges. Fig. 6 shows the pressure-time histories for each pressure gauge for both FT1 and FT2, where "RPB", "RPL", "RPR", and "RPT" refer to the bottom, left, right, and top pressure gauge for each test.

Both the FT1 and FT2 specimen exhibited damage in the concrete and CFRP. In the FT1 specimen, most of the concrete damage was located on the non-blast side of the specimen, with greater concrete damage located close to the location of the straps. There was also a significant amount of CFRP tearing located near the straps that spanned the width of the straps. This tearing was the greatest at the middle strap. Debonding occurred near the middle straps, similar to a previously reported failure mode, "plate-end debonding" [8], but this

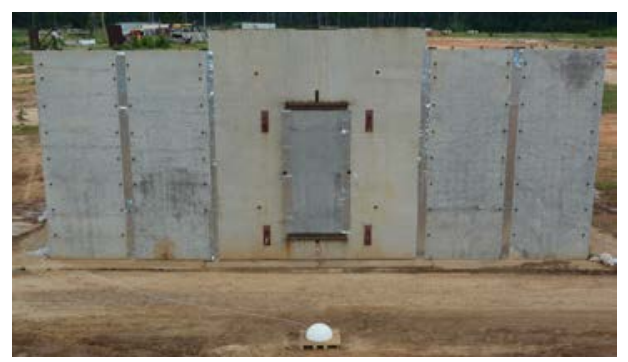

Figure 4: Finalized test setup before the blasting cap was installed. 

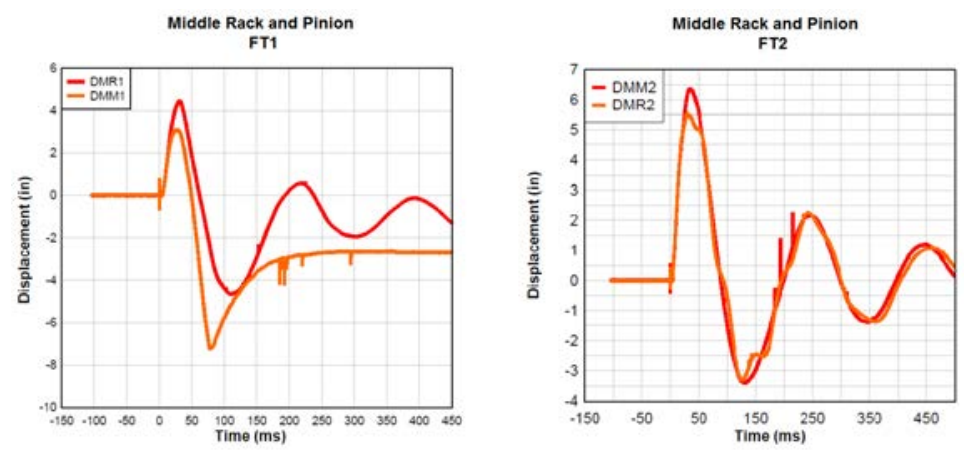

Figure 5: Displacement-time histories from the mid-height rack and pinions for FT1 (left) and FT2 (right).

Table 1: Peak reflected pressures and impulses.

\begin{tabular}{|c|c|c|c|}
\hline Test & Location & Peak pressure (MPa, psi) & Impulse (MPa-ms, psi-ms) \\
\hline FT1 & Bottom & $2.74,397.0$ & $2.51,364.5$ \\
& Mid-height (L) & $2.51,364.5$ & $2.36,342.3$ \\
& Mid-height (R) & $1.57,227.9$ & $1.89,273.9$ \\
& Top & $1.54,223.6$ & $1.53,222.1$ \\
\hline FT2 & Bottom & $6.38,925.4$ & $4.78,693.3$ \\
& Mid-height (L) & $4.69,680.2$ & $2.87,416.0$ \\
& Mid-height (R) & $3.84,557.0$ & $2.70,391.9$ \\
& Top & $1.92,278.8$ & $1.38,199.9$ \\
\hline
\end{tabular}
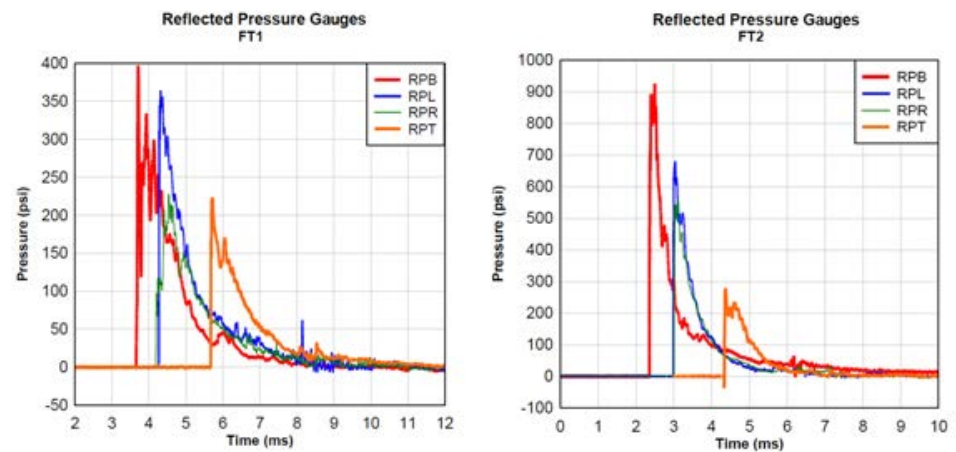

Figure 6: Pressure-time histories for each reflective pressure gauge for FT1 (left) and FT2 (right).

particular failure mode had never been reported before this test series. A small layer of concrete and even aggregate were still attached to the CFRP, indicating that no adhesive failure occurred. Fig. 7 is a post-test photo of the side of FT1, where the debonding and concrete failure near the middle strap can be seen. 


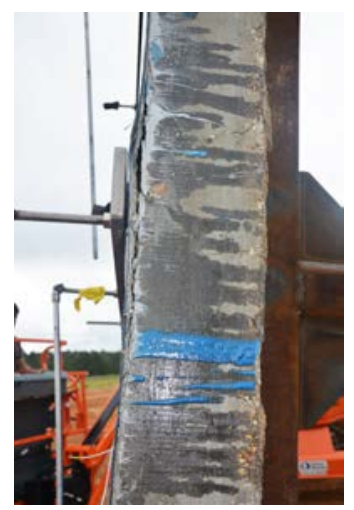

Figure 7: Concrete failure and debonding in FT1.
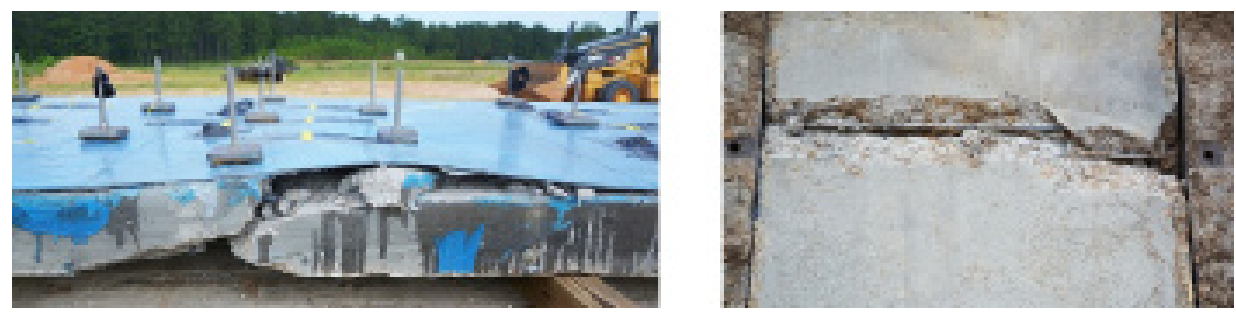

Figure 8: Intermediate crack-induced debonding (left) and concrete crushing (right) in the FT2 field test specimen.

In the FT2 specimen, similar to the FT1 specimen, most of the concrete damage occurred on the non-blast side of the specimen, but concrete crushing on the compressive side was also observed. Large flexural and flexural shear cracks were observed in the specimen. The location at which these cracks widened is the point at which debonding initiated in the retrofit. This debonding failure mode has been previously classified as "intermediate flexural and flexural shear crack-induced debonding" [8]. Despite the amount of damage in the FT2 specimen, widespread delamination was prevented as the smaller, more evenly distributed anchors allowed for a more even distribution of stresses. Small tears in the CFRP were observed near the anchors, but were not long in length, which indicates that using smaller anchors allows for less stress localizations to be induced in the specimen, as opposed to straps that span the width which caused much longer tearing in the CFRP. Fig. 8 shows two post-test photo of FT2, major flexural shear cracks and debonding (left), and concrete crushing (right).

\section{DISCUSSION OF EXPERIMENTAL RESULTS}

The experimental program was designed to estimate the pressure-time histories that would be imparted on the specimen. A finite element (FE) analysis and single degree of freedom (SDOF) analysis were conducted before the test to estimate the displacements. In the FT1 test, the displacements were much lower than predicted. These lower displacements could be due to a number of factors. In the FE and SDOF predictions, it was assumed that the reaction structure would be immobile, which it was not. Unfortunately, as it was unexpected for the 
reaction structure to move, no measurements were taken of the reaction structure, so it is not clear as to how much the structure moved. From the back-view high speed camera however, movement can be seen in the front slab of the reaction structure, and also in the first culvert section. Further proof of this movement was observed in the post-tension bars. Before the test, the nuts on the reaction structure's post-tension bars were tightened so that there was no space between the nuts and the washers, and after the test there was at least a $0.64 \mathrm{~m}$ ( 0.25 in) space - indicating that the post-tensioned slabs and culverts residually tightened by at least that amount. Therefore, it can be expected that movements greater than $0.64 \mathrm{~m}$ ( 0.25 in) occurred.

Another possible reason that the specimen moved far less than it was expected, was that the pressures obtained by most of the pressure gauges was far less than expected, by about $20 \%$ on average. This difference in the actual loading on the specimen which was much less than the predicted loading calculated on the specimen could be another factor in the unexpected low displacements of the specimen. This discrepancy between the predictions and what was actually measured could be due to a variety of factors. The charge was not placed directly on the ground, it was placed on a platform $8.89 \mathrm{~cm}$ (3.5 in) off of the ground. Furthermore, the ground that the platform was placed on was soil, not a rigid surface. A large

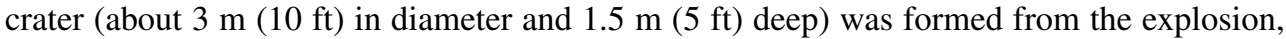
which could affect the pressures on the specimen.

Due to the lower than expected pressures in FT1 as well as indications that the front slab of the reaction structure moved a noticeable amount, changes were made for FT2 in order to obtain the higher desired displacements. The charge was moved $1.37 \mathrm{~m}(4.5 \mathrm{ft})$ closer to the specimen to obtain pressures and impulses closer to the expected loading, the remaining bottom gap between the front slab of the reaction structure and culvert was grouted, and the side gaps were filled up as much as possible with rubber and sandbags. FT2 exhibited lower displacements than predicted from the pre-test analyses, similar to FT1. Pre-FT2 test measurements and post-FT2 test measurements were taken of the reaction structure which indicated that despite the changes made to the reaction structure, the front slab of the reaction structure still moved a substantial amount.

It should also be noted, that similar to FT1, the pressures measured by the pressure gauges differed considerably from the UFC predictions. The trend that was seen in FT1 was not repeated in FT2. The comparison of the pressure gauge data for FT2 to the UFC predictions had more variability than the comparisons in FT1, and there was no clear trend as in FT1. Similar to FT1 a large crater was formed. The crater had a diameter of about $3.35 \mathrm{~m} \mathrm{(11 \textrm {ft } )}$ and was about $1.22 \mathrm{~m}$ ( $4 \mathrm{ft})$ deep. While there were substantial differences between the experimental pressures and the estimated calculated pressures, these discrepancies address the inherent unpredictability in explosive field tests and demonstrate the need for pressure gauges in experiments to measure the actual blast loads on specimen, so that comparisons between different experiments can remain relevant.

In FT1, there were long cracks that were parallel to the height of the specimen, suggesting that the governing failure mode was similar to what has been classified as "plate-end debonding" [8]. Concrete cover separation and plate-end interfacial debonding (shown in Fig. 9) are two more specific failure modes that can be classified as plate-end debonding failure modes. Plate-end debonding failures are not adhesive failures. These failures occur in the concrete, most likely due to high tensile or shear forces, and then can propagate as far as the steel reinforcement in the specimen and continue to move along the length of the slab, according to Teng et. al. [8]. Plate-end debonding failures are usually seen at the end of FRP plates due to the sudden change in stiffness at that point. This failure, however, occurred at and around the steel straps. Long cracks parallel to the steel reinforcement were observed to 


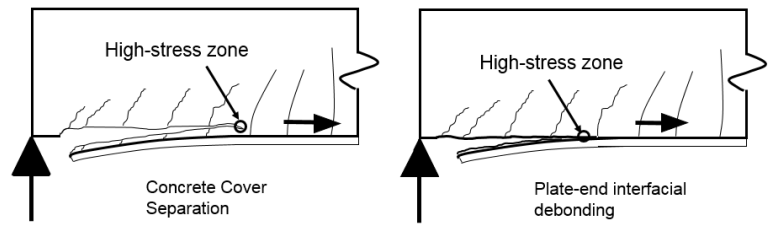

Figure 9: Schematic of plate-end debonding failures - concrete cover separation and plateend interfacial debonding.
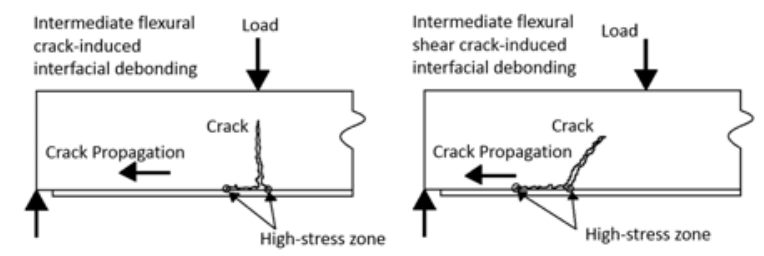

Figure 10: Schematic of intermediate flexural and flexural-shear crack-induced interfacial debonding.

begin and terminate near the steel straps, suggesting that the sudden change in stiffness of the specimen at those points resulted in a failure similar to plate-end debonding. The failure mode observed in FT1 was a new failure more that had never been reported before this test series [7]. This new failure mechanism is therefore classified as a "strap-induced debonding" failure mode, where the presence of the steel strap that spans the width of the specimen causes the abrupt change in stiffness that drives this failure mode.

In FT2 large flexural and flexural-shear cracks were formed, indicating that the failure mode in this slab was "intermediate flexural and flexural-shear crack-induced interfacial debonding", mixed with a compressive failure mode in the concrete due to the large cracks in the front face of the specimen. Intermediate flexural and flexural-shear crack-induced interfacial debonding occurs when a flexural or flexural-shear crack occurs far from a plate end and initiates the point of debonding of the CFRP and concrete. This debonding then propagates away from the initial point. This failure does not occur in the adhesive, but initiates in the concrete. A schematic of this failure is shown in Fig. 10.

While there was greater damage in the FT2 specimen, the debonding that occurred in the FT2 specimen was better contained than the debonding that occurred in the FT1 specimen. Therefore, it was found that using smaller anchors that are more evenly spaced, allows for widespread delamination to be prevented, especially compared to a strap system, as a more even distribution of stresses was allowed to develop in FT2.

\section{CONCLUSIONS}

Large concrete slab specimen with two different anchored CFRP retrofits were subjected to blast loading. The experimental program provided information on modes of failure (strap-induced debonding and intermediate crack-induced debonding) as well as maximum displacement of the slab system. The experimental program was the first reported test series that used an epoxy adhesive anchor system that was subjected to blast loads. The epoxy adhesive anchors performed well and it is recommended that future testing on these easy to 
install, cost effective anchors should be conducted. It was found that using smaller anchors that are more evenly spaced allow for a more even distribution of stresses in the retrofit system, and can prevent widespread delamination. Therefore, it is recommended that smaller, more evenly spaced anchor systems be used instead of a strap system for CFRP retrofits.

\section{ACKNOWLEDGEMENTS}

Support for this research was provided by the US Army Corps of Engineers Engineer Research and Development center, specifically the Survivability Engineering Branch (SEB) in the Geotechnical and Structures Laboratory, under the Force Protection in the Urban Environment program. The authors would like to thank Dr Catherine Stephens, Mr Omar Flores, Mr Steven Judson, and Mr Billy Bullock from SEB for their logistical support that made this test program possible.

\section{REFERENCES}

[1] Bonacci, J. \& Maalej, M., Behavioral trends of RC beams strengthened with externally bonded FRP. Journal of Composites for Construction, 5(2), pp. 102-113, 2001.

[2] Buchan, P. \& Chen, J., Blast resistance of FRP composites and polymer strengthened concrete and masonry structures - a state-of-the-art review. Composites Part B: Engineering, 38(5), pp. 509-522, 2007.

[3] Wu, C., Oehlers, D., Rebentrost, M., Leach, J. \& Whittaker, A., Blast testing of ultrahigh performance fibre and FRP-retrofitted concrete slabs. Engineering Structures, 31(9), pp. 2060-2069, 2009.

[4] Mosalam, K.M. \& Mosallam, A.S., Nonlinear transient analysis of reinforced concrete slabs subjected to blast loading and retrofitted with CFRP composites. Composites Part B: Engineering, 32(8), pp. 623-636, 2001.

[5] Triantafillou, T., Strengthening of structures with advanced FRPS. Progress in Structural Engineering and Materials, 1(2), pp. 126-134, 1998.

[6] Orton, S., Wheeler, M. \& Chiarito, V., Evaluation of mechanical anchoring system to improve performance of CFRP mitigated concrete slabs under close-in blasts. Structures Congress 2013: Bridging Your Passion with Your Profession, ASCE, pp. 239-249, 2013.

[7] Pezzola, G., Experimental Testing and Modeling Strategies of Carbon Fiber-Reinforced Polymer Blast Retrofits Using Steel Anchorage Systems. Ph.D. thesis, Georgia Institute of Technology, 2018.

[8] Teng, J., Chen, J.F., Smith, S.T. \& Lam, L., FRP: strengthened RC structures. Frontiers in Physics, p. 266, 2002.

[9] Mutalib, A.A. \& Hao, H., Numerical analysis of FRP-composite-strengthened RC panels with anchorages against blast loads. Journal of Performance of Constructed Facilities, 25(5), pp. 360-372, 2010.

[10] Muszynski, L.C. \& Purcell, M.R., Use of composite reinforcement to strengthen concrete and air-entrained concrete masonry walls against air blast. Journal of Composites for Construction, 7(2), pp. 98-108, 2003. 